\title{
Breast-feeding practices in Mexico: Results from the Second National Nutrition Survey 1999
}

\author{
Teresa González-C ossío, MSc, PhD, ${ }^{(1)}$ Hortensia Moreno-Macías, MSc, ${ }^{(1)}$ \\ Juan A Rivera, MS, PhD, (1) Salvador Villalpando, MD, PhD, (1) Teresa Shamah-Levy, BSC, ${ }^{(1)}$ \\ Eric A Monterrubio, BSc, ${ }^{(1)}$ A dolfo Hernández-Garduño, MD, MSc. ${ }^{(2)}$
}

\begin{abstract}
González-Cossío T, Moreno-Macías H, Rivera JA, Villalpando S, Shamah-LevyT, Monterrubio EA, Hernández-Garduño A. Breast-feeding practices in Mexico: Results from the Second National Nutrition Survey,1999.

Salud Publica Mex 2003;45 suppl 4:S477-S489.

The English version of this paper is available too at: http://www.insp. mx/salud/index.html
\end{abstract}

\begin{abstract}
A bstract
Objective. To assess breast-feeding (BF) practices and determinants of exclusive BF (EBF) $<4$ and $<6$ months (mo) among women and infants <23 mo in the N N S-1999. Ma terial and Methods. BF practices from the day and night before the interview were ascertained, and median duration estimated. Determinants of $\mathrm{EBF}<4$ and $<6$ mo were analysed by logistic regression models for complex surveys. Results Prevalence of EBF $<4$ mo was $25.7 \%$, and of $<6$ mo $20.3 \%$. The overall rate of continued BF (second year) was $30.9 \%$, median duration of BF $9 \mathrm{mo}$, and the national proportion of children ever breast-fed $92.3 \%$. The probability (p) of EBF $<4$ mo was determined by infant age and sex, by maternal socio-economic level (SEL) and ethnicity, and by the interaction between infant sex and SEL.The pEBF $<6$ mo was determined by infant age and length, by maternal ethnicity, and employment. Conclusions EBF rates and duration are low in Mexico and have improved only slightly in the last $20 \mathrm{y}$. Infant and maternal characteristics determine the $p E B F$. If improvements in infant health are a national priority, aggressive interventions to promote and protect $\mathrm{BF}$ are urgently needed in Mexico, as well as formal evaluation of current initiatives. The English version of this paper is available too at: http://www.insp.mx/salud/index.html
\end{abstract}

Key words: breast-feeding practices; exclusive breast-feeding, breast-feeding duration; Mexico

\author{
González-CossíoT, Moreno-Macías H, Rivera JA, \\ Villalpando S, Shamah-LevyT, \\ Monterrubio EA, Hernández-Garduño A. \\ Prácticas de lactancia en México: resultados \\ de la Segunda Encuesta Nacional de Nutrición 1999. \\ Salud Publica Mex 2003;45 supl 4:S477-S489. \\ El texto completo en inglés de este artículo también \\ está disponible en: http://www.insp.mx/salud/index.html
}

\section{Resumen}

Objetivo. Evaluar las prácticas de lactancia y las determinantes de la lactancia exclusiva (LE) hasta $<4$ y $<6 \mathrm{~m}$, en mujeres con hijos menores de $24 \mathrm{~m}$ de la segunda Encuesta $\mathrm{N}$ acional de Nutrición 1999. Material y métodos. Las prácticas de lactancia se estimaron del día y la noche anteriores a la entrevista. Los determinantes de $L E<4 m$ y $L E<6 m$ fueron analizados mediante regresión logística para muestras complejas. Resultados La prevalencia de $L E<4 m$ fue $25.7 \%$, y $<6 \mathrm{~m} 20.3 \%$. La tasa de lactancia continuada (segundo año) 30.9\%, mediana de duración de lactancia $9 \mathrm{~m}$, y proporción de amamantados alguna vez $92.3 \%$. La probabilidad (p)LE<4m estuvo determinada por edad, y el sexo del infante, por el nivel socioeconómico y etnicidad maternas, y por la interacción entre el sexo y el nivel socioeconómico. La $p L E<6 m$ estuvo determinada por edad y la longitud del infante y por el empleo, etnicidad y nivel socioeconómico de la madre. Conclusiones La duración y prevalencia de LE son bajas en México, poco mejores que hace 20 años. Las características del infante y de la madre determinan la $p$ LME. Para promover la salud del niño, es urgente implementar programas agresivos de protección y promoción de la lactancia, así como evaluar y adecuar formalmente los existentes. El texto completo en inglés de este artículo también está disponible en:http://www.insp.mx/salud/index.html

Palabras clave: prácticas de lactancia materna; lactancia materna exclusiva; duración de la lactancia materna; México

Portions of this paper were presented at Experimental Biology, 2002; N ueva O rleans, Louisiana as: Breast-feeding practices in Mexico: Results of the Second N ational N utrition Survey 1999. Abstract A65.4.

(1) Instituto Nacional de Salud Pública, Centro de Investigaciones en N utrición y Salud. Cuernavaca, Morelos, México.

(2) Hospital General de México. Secretaría de Salud. México, D F, México.

Received on: August 20,2002 • Accepted on: September 12,2003

Address reprint requests to: D ra.Teresa González-C ossío, Avenida Universidad 655, colonia Santa María A huacatitlán, 62508 Cuernavaca, Morelos, México. 
$\mathrm{H}$ uman milk is the most appropriate food for infants, and contains highly nutritive substances. ${ }^{1}$ Breast-feeding increases the infant's opportunities for survival $^{2,3}$ promotes better health ${ }^{4-6}$ nutritional status ${ }^{7}$ and cognitive development ${ }^{8}$ and appears to be a protective factor against overweight later in life. ${ }^{9}$ Breastfeeding also brings advantages to maternal health. Women who breast-feed have a reduced risk of breast cancer. ${ }^{10-12}$ Lactating mothers experience a lowered fertility ${ }^{13-15}$ which has implications for population growth. And those who nurse exclusively for $6 \mathrm{mo}$, loose more weight and at higher speed after delivery ${ }^{16}$ than those who do not breast-feed as intensely. This effect of exclusive breast-feeding on weight loss is of public health importance in the face of a dramatic increase in the prevalence of obesity over the last decade in Mexico, and of the present nutritional transition the country is experimenting. ${ }^{17}$

Breast-feeding practices in Mexico are poor relative to other countries in Latin America. ${ }^{18}$ Median duration of lactation has been reported to be under 9 months in Mexico, ${ }^{19,20}$ when other countries reported 18 months. ${ }^{18}$ The only previous Mexican national data documenting exclusive breast-feeding patterns were collected in $1979^{21}$ and for infants below 3 mo of age, it was estimated to be $15.3 \%$. Five national surveys conducted during the 70's and 80's s, $^{19,22-24}$ offer information on infant feeding behaviour by maternal recall, and describe poor lactation practices in the country. Low rate of initiation (between $89.3 \%$ in 1976 to $77.6 \%$ in 1979) and a short ( $\leq 8.7 \mathrm{mo})$ median duration of breast-feeding (reported for two surveys: 1.1 mo for infants $<12$ mo in 1986, from the National Health Survey (Encuesta Nacional de Salud -ENSA-) ${ }^{20}$ and 8.7 mo in the Mexican Fertility Survey (Encuesta Mexicana de Fecundidad -EMF-) in 1976). ${ }^{19}$ However, infant feeding practices had improved somewhat in the past two decades. For example, the percentage of infants never breast-fed, had declined from close to $22 \%$ in $1979^{22}$ to approximately $14 \%$ in the first National Nutrition Survey $1988 .^{24}$

According to the World Health Organization (WHO) ${ }^{25}$ infants should be fed exclusively at the breast for the first 6 mo of life, and continue breast-feeding for $2 \mathrm{y}$ or more if the mother-infant dyad so desire. The country's progress should be measured against this target.

In this paper we report the breast-feeding practices estimated from the National Nutrition Survey-1999 (NNS-1999) conducted in Mexico from October 1998 through March 1999. The survey was representative at the national level, for 4 regions, and for rural and urban populations. ${ }^{26}$ Relevant nutritional, demographic and socio-economic variables were used to describe the practices for different groups within the country, and used as predictors of exclusive-breast-feeding (EBF) for $<4$ and $<6$ months.

\section{Material and Methods}

Materials. We used digital baby scales (Tanita, Tokyo, Japón Model 1583) to measure weight in children weighing up to $10 \mathrm{~kg}$ with a lecture precision of $10 \mathrm{~g}$, and of $20 \mathrm{~g}$ for weight between 10 and $20 \mathrm{~kg}$. Fibre glass stadiometers (locally constructed) were used to measure length $(<2 y)$ or height $(>2 y)$. Standardisation procedures were conducted prior to data collection to minimise technical measurement error.

\section{Subjects}

Women of reproductive age (12 to $49 y$ ) and their live children $<2 \mathrm{y}$ of age who lived in the selected household at the time of the survey, were included in the analyses. Information on diseased children was not collected, thus not included in any calculation.

Methods. This was a national cross-sectional survey conducted in Mexico to evaluate the nutritional status, and its main determinants, of Mexican children and women of reproductive age.

Definitions. Exclusive breast-feeding was defined as consuming nothing but breast milk. Rates were calculated for $<4$ and $<6$ mo of age (i.e., for 0 to 123 days (d) and 0 to $<183 \mathrm{~d}$ of life), and monthly by completed months as recommended by Lung'aho et al ${ }^{23}$ (i.e., 0 $\mathrm{mo}=0-30 \mathrm{~d}, 1 \mathrm{mo}=31-61 \mathrm{~d}, 2 \mathrm{mo}=62-91 \mathrm{~d}, 3 \mathrm{mo}=92-122$ d, 4 mo=123-152 d, 5 mo=153-182 d). Ever breast-fed was defined as having ever suckled at the breast to receive colostrum or breast milk. Continued breast-feeding rates were calculated as recommended, from the number of children aged 12 to $<16$ mo and from 20 to $<24$ mo who received breast milk the day before the interview. Median duration of any breast-feeding was estimated through moving averages, and by the Kaplan-Meier method. Results were the same, and moving averages are presented.

Independent variables included anthropometric and demographic characteristics of mothers and their infants, and are presented in Table I.

Sampling technique. A national probabilistic sample was collected, representative of 4 regions (North, Center, 
Table I

\section{DESCRIPTIVE CHARACTERISTICS OF THE MOTHERS AND CHILDREN < 24 MONTHS PARTICIPATING in the National Nutrition Survey, Mexico, 1999}

\begin{tabular}{|c|c|c|c|c|c|c|c|c|c|}
\hline \multirow[b]{3}{*}{$n^{\S}$} & \multirow{2}{*}{$\begin{array}{c}\% \text { or M ean (SD) } \\
\text { National }\end{array}$} & \multicolumn{4}{|c|}{ Region* } & \multicolumn{2}{|c|}{ Stratum } & \multicolumn{2}{|c|}{ Indigenous ${ }^{\ddagger}$} \\
\hline & & North & Center & Mexico City & South & Urban & Rural & Yes & No \\
\hline & 3,192 & 921 & 1003 & 239 & 1029 & 1891 & 1301 & 319 & 2772 \\
\hline $\mathrm{N}^{\#}$ & 3757542 & 733134 & 1270980 & 504477 & 1248951 & 2614896 & 1142646 & 365131 & 3264027 \\
\hline $\mathrm{N}$ ational $(\%)$ & 100 & 19.5 & 33.8 & 13.3 & 33.2 & 69.6 & 30.4 & 10.1 & 89.9 \\
\hline N umber of children & $2.7 \quad(2.0)^{\&}$ & $2.3 \quad(1.5)$ & $2.9 \quad(2.2)$ & (1.4) & $3.0^{\varnothing} \quad(2.2)$ & $2.4 \quad(1.7)$ & $3.4 \quad(2.4)$ & $3.6(2.4)$ & $2.6^{\sigma} \quad(1.9)$ \\
\hline Employed $\neq$ (\% yes) & 30.5 & 31.3 & 29.1 & 31.4 & 31.1 & 33.6 & 23.3 & 35.8 & 29.9 \\
\hline Schooling (y) & $7.4 \quad(4.4)$ & $8.6 \quad(3.7)$ & $7.2 \quad(4.2)$ & $9.4 \quad(4.5)$ & $6.2 \quad(4.4)$ & $8.5 \quad(4.3)$ & $4.9 \quad(3.4)$ & $4.3(3.9)$ & $\begin{array}{ll}7.9^{\circ} & (4.2)\end{array}$ \\
\hline Age (y) & $26.6 \quad(6.2)$ & $25.9 \quad(6.0)$ & $26.9 \quad(6.2)$ & 26.8 & $26.7^{ø} \quad(6.5)$ & $26.7 \quad(6.1)$ & $26.5 \quad(6.6)$ & $26.8(6.7)$ & $26.6 \quad(6.2)$ \\
\hline Spouse (\% present) & 88.8 & 90.5 & 88.5 & 84.5 & $89.9^{\circ}$ & 87.7 & 91.5 & 92.6 & $88.7^{\circ}$ \\
\hline Health services & 48.3 & 66.5 & 44.8 & 61.8 & $35.9^{\circ}$ & 57.2 & $28.2^{\circ}$ & 35.4 & $49.5^{\circ}$ \\
\hline Food aid (\% receiving) & 26.4 & 14.0 & 21.2 & 34.4 & $35.6^{\infty}$ & 19.6 & $41.8^{ø}$ & 42.3 & $24.9^{\circ}$ \\
\hline Child gender (\% males) & 50.7 & 48.9 & 50.2 & 54.4 & 50.8 & 49.8 & 48.4 & 52.7 & 50.5 \\
\hline SES (score) ${ }^{\infty} \%$ lower tertile & 32.9 & 12.0 & 30.7 & 14.5 & $54.9^{\circ}$ & 18.3 & 66.3 & 73.9 & $28.2^{ø}$ \\
\hline$\%$ upper tertile & 31.5 & 46.8 & 30.2 & 43.7 & 18.9 & 41.8 & 7.9 & 8.1 & 34.5 \\
\hline W eight $(\mathrm{kg})$ & $60.4(12.2)$ & $65.4(13.3)$ & $61.5(11.6)$ & $60.3 \quad(11.3)$ & $56.3^{ø}(10.4)$ & $62.0(12.1)$ & $56.7(10.9)$ & $53.8(9.5)$ & $61.1^{ø}(12.0)$ \\
\hline Height $(\mathrm{cm})$ & $152.7 \quad(6.6)$ & $155.4 \quad(6.4)$ & $153.8 \quad(6.3)$ & 153.1 & $149.7^{\varnothing} \quad(6)$ & $153.7 \quad(6.4)$ & $150.3 \quad(6.6)$ & $147.6(5.8)$ & $153.2^{ø} \quad(6.4)$ \\
\hline $\mathrm{BMI}\left(\mathrm{kg} / \mathrm{m}^{2}\right)$ & $25.7 \quad(4.6)$ & $27.0 \quad(5.1)$ & $25.9 \quad(4.5)$ & 25.7 & $24.9^{\circ} \quad(4.1)$ & $26.2(4.6)$ & $24.9 \quad(4.2)$ & $24.5(3.9)$ & $25.9^{\varnothing} \quad(4.6)$ \\
\hline
\end{tabular}

\footnotetext{
* Region: N orth, Center, Mexico City, and South (for specific states within each region, see in text)

₹ Mother speaks an indigenous language

§ Sample size

\# Estimated population size

$\&$ Mean (SD)

* Reports holding a job or having some economic activity from which she perceived money in exchange, the week prior to the interview

${ }^{\infty}$ Calculated through principal components analysis

$\stackrel{0}{\infty}<0.05$
}

Mexico City, and South), ${ }^{*}$ and rural (pop <2500) and urban areas (pop $\geq 2500$ ). Families were selected according to a sampling frame developed by INEGI (acronym from its Spanish name; Mexican National Institute of Statistics, Geography and Information), described in detail elsewhere. ${ }^{26}$ All households with women between the ages of 12 and $49 y$, and or children $<12$ $\mathrm{y}$ of age, were included in the population from which

\footnotetext{
* North (Baja California, Baja California Sur, Coahuila, Chihuahua, Durango, Nuevo León, Sonora and Tamaulipas). Center (Aguascalientes, Colima, Guanajuato, Jalisco, México (excludes urbanised counties and localities adjacent to Mexico City), Michoacán, Morelos, Nayarit, Querétaro, San Luis Potosí, Sinaloa, Zacatecas). Mexico City (includes Federal District and urbanised counties from the state of Mexico). South (Campeche, Chiapas, Guerrero, Hidalgo, Oaxaca, Puebla, Quintana Roo, Tabasco, Tlaxcala, Veracruz, Yucatán).
}

the sample was drawn. The data presented here pertain to children $<2 \mathrm{y}$ of age living in the selected families. There were no exclusion criteria. Uninhabited $(9.8 \%)$, non identified households $(1.9 \%)$, and non-response $(5.9 \%)$, were the causes of no data collection. Data were collected from the $82.4 \%$ of the households in the sample frame who responded. Written informed consent was obtained after explaining the purpose and methods of the survey from all adult participants, and from children's guardians, before data were collected.

Data collection. Data on breast-feeding practices were collected using two methodologies: status quo and recall data, as recommended by the WHO.$^{25}$ Briefly, status quo data describe what the child under $2 \mathrm{y}$ of age was fed the day and the night before the interview. For recall data the mother is asked to recall the age when specific infant feeding practices occurred. Mothers were asked at what age their child was fed consistent- 
ly at least one food item from each of 7 food groups. The 7 groups were as follows: 1) plain water, 2) nonbreast milk, 3) non-nutritive liquids (sugared water and other water-based drinks including teas, bean or chicken broth, coffee, soft drinks, or 'agua miel'; ; but not fruit juices, 4 ) other liquids (thinned gruel with water or milk, another cereal with water or milk, coffee with milk, fruit juices), 5) cereals and legumes (pastas, rice, tortillas, bread, oats, beans, lentils, fava beans and similar beans); 6) fruits and vegetables; and 7) meat, milk products, and eggs).

Because recall data are based on asking the mother at what specific age she fed her child a certain food group, we used data from all children $<2 y$ to estimate breast-feeding duration. Alternatively, status quo data uses the information provided by the mother, to define her infant feeding practices the day and night before the interview. Thus the recall method provides larger sample size but has potential recall biases. The status quo method (also called current data) is based on a smaller sample size but assumed to have greater validity to describe breast-feeding practices. ${ }^{27}$ We only used recall data to estimate median duration of breastfeeding of children $<24$ mo. This way we had information on those infants who had been breastfed but had stopped breast-feeding at the time of the survey. We used status quo data for prevalences and to estimate the probabilities of exclusive breast-feeding.

Prior to the survey, observers were trained in all areas of data collection by trained and standardised supervisors. During data collection, supervisors reviewed data every night, and if inconsistencies or missing data were identified, the observer was asked to return the next day to the designated households. This strategy was implemented to minimise inconsistencies and missing data in the field.

Statistical analyses. The outcome variables were breastfeeding practices analysed either: a) as proportions, b) as medians, or c) as dependent variables in logistic regression models.

a) The proportion of exclusive breast-feeding infants $<4$ months was calculated by dividing the total number of children exclusively breast-fed from birth to $<123 \mathrm{~d}(<4 \mathrm{mo})$ by the total number of infants $<123 \mathrm{~d}$, regardless of their feeding mode. Proportions for $<6$ mo were calculated similarly, but for $<183 \mathrm{~d}$. The indicator of early (12 to $<16$ $\mathrm{mo})$ and late $(20$ to $<24 \mathrm{mo})$ rates for continuation

\footnotetext{
* Agua miel: unfermented syrup from the agave core.
}

of breast-feeding, as well as the overall rate of continued breast-feeding in the complete second year of life ( $>365$ to $<731 \mathrm{~d})$, were calculated as recommended. ${ }^{27}$

We used status quo data to estimate these proportions.

b) Median duration of breast-feeding was calculated by two methods: Kaplan-Meier ${ }^{28}$ and 3-monthrunning averages, assigned to the middle month. We used recall data. Because we collected data on children $<2 y$, and there are children who breastfeed longer, calculated medians may underestimate the true duration. This underestimation is usually not large because most of the breast-feeding takes place during the first $2 y$ of life. The magnitude of the underestimation depends on the distribution of feeding practices by age.

c) Logistic regression models for complex surveys ${ }^{29}$ were used to predict the probability of being exclusively breast-fed for 4 mo or less $(p \mathrm{EBF}<4)$ and for 6 mo or less $(p \mathrm{EBF}<6)$ using status quo data. Probabilities of exclusive breast-feeding were calculated. The inverse of the sample probabilities of being selected were used as sample weights.

For many years, the WHO recommendations regarding the duration of exclusive breast-feeding provided a range of 4 to 6 mo rather than a specific duration. Since March 2001, the recommendation is specific: 6 mo of EBF. Thus, for some time, reaching at least 4 mo was the target, which has changed to $6 \mathrm{mo}$ now. For this reason, we analysed the probabilities of being exclusively breast-fed for both age targets: $<4$ and $<6$ mo.

Several biologically meaningful and socially important determinants of breast-feeding practices were considered to describe the sample and to construct the regression models. For women these were: number of children, ethnicity (whether or not she speaks a native language), maternal schooling (last grade approved at school, in y), age (y), employment (yes/no), ${ }^{*}$ if living with a partner (yes/no), family's socio-economic level (SEL, an index constructed through a principal components analysis) ${ }^{30}$ nutritional status: (weight $(\mathrm{kg})$, height $(\mathrm{m})$, and body mass index $\left.\left(\mathrm{kg} / \mathrm{m}^{2}\right)\right)$, being a beneficiary of any kind of government food

\footnotetext{
* Reports holding a job or having some economic activity from which she perceived money in exchange, the week prior to the interview.
} 
aid* (yes/no), and access to health care system $^{\ddagger}$ (insured or not). Infants' characteristics considered were: gender, weight and length. We also took into consideration the family's place of residence: region (North, Center, South, and Mexico City), and type of setting (rural/urban). Meaningful interactions were evaluated as well. These included two-way interactions of any of the following two variables: SEL, maternal schooling, place of residence, ethnicity, number of children, maternal employment, and infant gender and length. Cuadratic relationships were evaluated for the relationship between the $p \mathrm{EBF}<4$ or $p \mathrm{EBF}<6 \mathrm{mo}$, and maternal age, maternal schooling, SEL, number of children, and infant age.

Bivariate relationships were first evaluated. Those associations with $p$ values $<0.25$ were entered into a full model. A backwards elimination procedure was followed to reach a model which contained independent variables with a statistical association with breastfeeding practices of $p<0.05$. Forward procedure was used to test the backward selection. The models' goodness of fit was tested with the Hosmer-Lemeshow test. ${ }^{31}$ Both models had a $p>0.23$. Multicollinearity was evaluated through decomposing the models' matrix of eigenvalues, and evaluating the ratio of the highest over the lowest eigenvalue. ${ }^{32}$ Models with values over 10 were not accepted.

Final models contain variables that were statistically significant after the procedure described above and variables that, based on subject matter considerations, are considered important regardless of their statistically significant level.

Descriptive statistics of the study population are presented (Table II); means \pm standard deviations (SD) for continuos, and percentages for categorical variables. Student's $t$ tests for means, and $\chi^{2}$ for proportions, were performed to compare data among the strata for each exclusive breast feeding group. Data entry was done with Fox Pro ${ }^{\S}$ and statistical analysis with Stata ${ }^{\#}$ (version 7.0, 2001)

\footnotetext{
* Any person of the household receiving from the government one or more of the following food items: milk, tortillas, maize or wheat flour, rice, beans, oil, pasta, sugar, salt, school breakfast, Progresa infant or maternal supplement, sardines, crackers or cookies, or other).

‡ Access to a partial or complete health insurance provided either by the government (IMSS, SSA ISSSTE, Pemex, Army or Navy), or by a private employer.

$\S$ Microsoft Visual Fox Pro Release 6. Seattle (WA): Microsoft Corporation, 1998-1999.

\# Stata Statistical Software:Release 7.0 College Station (TX): Stata Corporation, 2001.
}

\section{Results}

Characteristics of study subjects. Table I presents the demographic, social and anthropometric characteristics of the families with children $<24$ mo of age, stratified by region, urban or rural stratum, and ethnic group (indigenous yes/no). Families have less than three children on the average; this is highest for indigenous families. Slightly less than one out of every 3 (30.5\%) women in reproductive age reported to have been employed in the last week in Mexico; this was also highest (35.8\%) for indigenous women. The average number of years of maternal schooling was one year above completed primary (7.4y). While in Mexico City it was slightly above secondary school (9.4y), for indigenous mothers it was only $4.3 y$. The average maternal age was 26.6y. Almost 9 out of every 10 mothers $(88.8 \%)$ in the sample had a spouse at the time of the survey. Half of the families had any kind of pre-arranged health service $(48.3 \%)$ with large differences among the categories, but rural areas, indigenous families, and the south region had much lower percent families with health service coverage than comparable strata.

Somewhat over one quarter $(26.4 \%)$ of the families received some kind of government food aid* with larger proportions among families from the rural or of indigenous origin. Combining all types of governmental food aid, a very similar proportion of families received it in the metropolitan than in the south region, but analysing food aid by urban or rural location, the percent of beneficiaries in rural area $(41.8 \%)$ was twice as high as that in the urban area $(19.6 \%)$. As expected, half the children were males. Mothers were somewhat heavy $(60.4 \mathrm{~kg})$ and short $(152.7 \mathrm{~cm}$ on the average), and had an average body mass index $\left(\mathrm{kg} / \mathrm{m}^{2}, \mathrm{BMI}\right)$ of 25.7 ; above the cut-off point used to classify overweight.

Breast-feeding proportions. Figure 1 presents breast-feeding practices by completed months through the first two years of life. Proportions are presented for exclusive, full, and any type of breast-feeding, as reported by the status quo method. Data show that breast-feeding practices decline rapidly with age, the largest decline occurring during the first six months of life. Exclusive breast-feeding is the most rare of the prac-

\footnotetext{
* Any person of the household receiving from the government one or more of the following food items: milk, tortillas, maize or wheat flour, rice, beans, oil, pasta, sugar, salt, school breakfast, Progresa infant or maternal supplement, sardines, crackers or cookies).
} 
Table II

\section{BREAST-FEEDING PRACTICES BY SOCIO-ECONOMIC, DEMOGRAPHIC AND ANTHROPOMETRIC CHARACTERISTICS. National Nutrition Survey, Mexico, 1999}
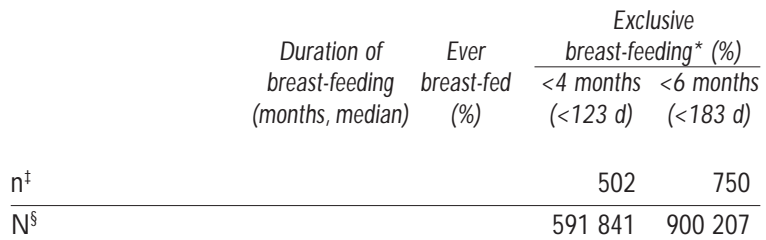

$\begin{array}{lllll}\text { National } & 9 & 92.3 & 25.7 & 20.3\end{array}$

Region*

\begin{tabular}{lrrrr} 
N orth & 6 & 91.8 & 16.5 & 10.5 \\
\hline Center & 8 & 91.6 & 25.0 & 19.1 \\
\hline Metropolitan Area & 7 & 92.0 & 11.6 & 12.3 \\
\hline South & 15 & 93.5 & $36.5^{ø}$ & $30.5^{ø}$
\end{tabular}

Locality

\begin{tabular}{lrrrr} 
Urban & 7 & 92.3 & 20.9 & 15.0 \\
\hline Rural & 14 & 92.2 & $36.1^{ø}$ & $33.2^{ø}$
\end{tabular}

Ethnicity ${ }^{\#}$

\begin{tabular}{lrrrr} 
Indigenous & $>24$ & 93.5 & 48.2 & 48.4 \\
\hline N on-indigenous & 8 & 92.3 & $23.2^{\varnothing}$ & $17.8^{\varnothing}$
\end{tabular}

Socio-economic level ${ }^{*}$

\begin{tabular}{lrrrl} 
Low & 15 & 92.3 & 39.8 & 33.8 \\
\hline Midde & 8 & 91.6 & 17.3 & 14.2 \\
\hline High & 6 & 93.1 & $20.7^{ø}$ & $14.3^{\circ}$
\end{tabular}

Maternal employmento

\begin{tabular}{rrrrr} 
Yes & 7 & 93.0 & 18.0 & 13.4 \\
\hline N o & 11 & 92.2 & $28.6^{\sigma}$ & $22.7^{\varnothing}$
\end{tabular}

Spouse present

\begin{tabular}{rrrrr} 
Yes & 10 & 92.9 & 26.7 & 21.2 \\
\hline N o & 6 & 90.4 & 19.4 & 14.1
\end{tabular}

N umber of children

\begin{tabular}{crrrr}
1 & 7 & 94.1 & 22.8 & 16.6 \\
\hline 2 & 8 & 91.6 & 26.1 & 19.9 \\
\hline$\geq 3$ & 12 & 91.5 & 27.8 & 23.6
\end{tabular}

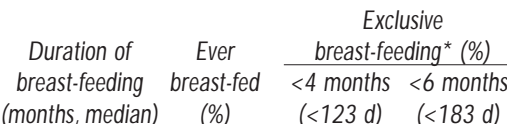

Maternal age (y)

\begin{tabular}{lrrrr}
$<19$ & 12 & 92.2 & 27.6 & 23.1 \\
\hline 19 to $<25$ & 10 & 93.5 & 24.5 & 21.6 \\
\hline 25 to $<35$ & 8 & 92.2 & 25.9 & 18.3 \\
\hline$\geq 35$ & 9 & 89.9 & 26.5 & 20.8
\end{tabular}

Schooling (y completed in school)

\begin{tabular}{lrrrc}
$<1$ & 14 & 88.9 & 41.5 & 37.2 \\
\hline 1 to $<6$ & 12 & 90.8 & 29.2 & 23.9 \\
\hline 6 to $<9$ & 12 & 92.8 & 29.3 & 23.3 \\
\hline 9 to 12 & 7 & 92.7 & 23.7 & 17.1 \\
\hline 12 to $<14$ & 6 & 93.9 & 27.0 & 20.2 \\
\hline$\geq 14$ & 6 & $94.0^{\circ}$ & $3.7^{\circ}$ & $2.6^{\circ}$
\end{tabular}

Health Services

\begin{tabular}{|c|c|c|c|c|}
\hline Yes & 7 & 93.5 & 23.9 & 17.8 \\
\hline No & 12 & $91.5^{\circ}$ & $28.3^{\circ}$ & $23.4^{\sigma}$ \\
\hline \multicolumn{5}{|c|}{ Maternal height $(\mathrm{cm})$} \\
\hline$<$ mean & 14 & 93.0 & 34.2 & 28.3 \\
\hline$\geq$ mean & 7 & 91.8 & $18.2^{\circ}$ & $3.8^{\circ}$ \\
\hline
\end{tabular}

Body mass index $\left(\mathrm{kg} / \mathrm{m}^{2}\right)$

\begin{tabular}{lrlll}
$<$ mean & 10 & 93.6 & 33.2 & 25.7 \\
\hline$\geq$ mean & 8 & $91.2^{ø}$ & $16.9^{\varnothing}$ & $14.7^{ø}$
\end{tabular}

Child gender

\begin{tabular}{lllll} 
Girl & 9 & 92.6 & 31.7 & 24.0 \\
\hline Boy & 9 & 92 & $20.2^{\infty}$ & $16.9^{\circ}$
\end{tabular}

Infant length $(\mathrm{cm})$

\begin{tabular}{lrrrr}
$<$ mean & $>20$ & 92.9 & 31.7 & 24.0 \\
\hline$\geq$ mean & 8 & 92.0 & $21.2^{\varnothing}$ & $15.8^{\varnothing}$
\end{tabular}

* Exclusive breast-feeding: receiving $0 \mathrm{~N}$ LY breast-milk (consumption of pharmaceutical products (medicines or vitamin-mineral preparations) were not explored)

₹ Sample size

$\S$ Estimated population size

\# Region: N orth, Center, Mexico City, and South (for specific states within each region, see in text)

$\&$ Indigenous: mother speaks a native language

* Calculated through principal components analysis

${ }^{\infty}$ Reports holding a job or having some economic activity from which she perceived money in exchange, the week prior to the interview

${ }_{0}<0.05$

tices; slightly over one third (39\%) of infants $<1$ month were fed exclusively at the breast, and only $86.9 \%$ of them receive breast milk at this age.

As indicators of early $(12$ to $<16 \mathrm{mo})$ and late $(20$ to $<24 \mathrm{mo}$ ) rates for continuation of breast-feeding, the percentage of children still at the breast at these ages was estimated. One third $(36.2 \%)^{27}$ and one quarter ( $25.3 \%)$ of the children continue to breast-feed in these two stages respectively. The overall rate of continued breast-feeding in the complete second year of life ( $>365$ to $<731 \mathrm{~d}$ ) is $30.9 \%$.

Breast-feeding practices by categories of demographic, socio-economic and anthropometric char- 


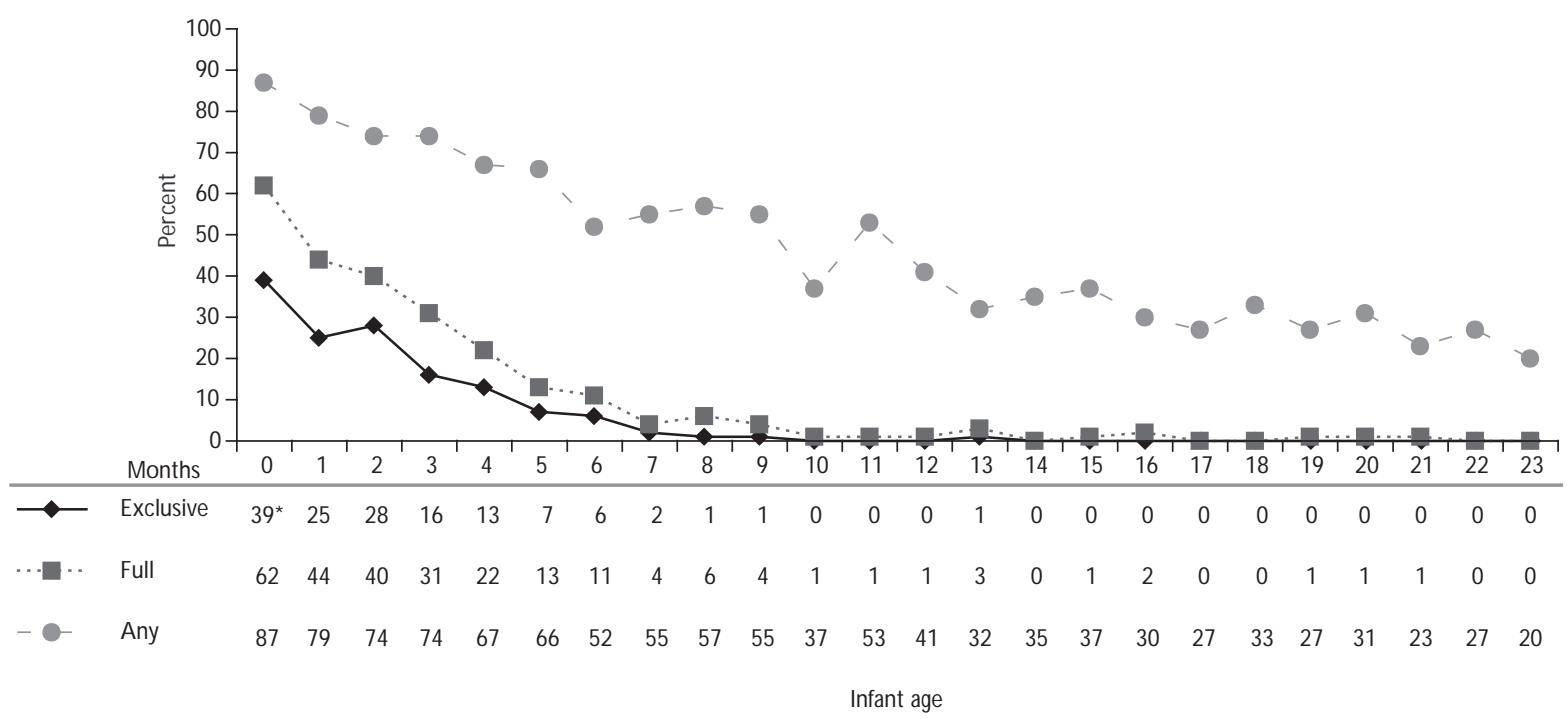

Figure 1. Breast-feeding practices in Mexico. National Nutrition Survey, Mexico, 1999. Proportion of EXCLUSIVE, FULL AND ANY BREAST-FEEDING BY COMPLETED MONTH OF INFANT AGE (*\% ROUNDED UP TO THE NEAREST INTEGER)

acteristics are presented in Table II. The estimated national median duration of breast-feeding was 9 months. Duration was longest in the group of indigenous mothers where more than $50 \%$ of the children were still breast-fed at $24 \mathrm{mo}$; thus median duration could not be calculated in these ethnic group, but it is certainly longer than 24 mo. The next longest breastfeeding duration was for those mothers whose infants were below the population median length $(>20 \mathrm{mo})^{*}$ followed by those in the south and in the low SEL (15 mo), the rural area, mothers without formal schooling, and whose height was below the sample mean $(14 \mathrm{mo})$. The shortest median breast-feeding duration $(6 \mathrm{mo})$ was found in the north region, in the high SEL, in those not having a spouse present, and in those with $\geq 12 \mathrm{y}$ of maternal schooling. The national percent of children in Mexico who were ever breast-fed was $92.3 \%$. This figure ranged from $88.9 \%$ (those with no maternal schooling) and $94.0-94.1 \%$ (those with 1 child and those with $>14 \mathrm{y}$ of maternal schooling), with little differences among subgroups. However, the differences in proportions within categories of schooling, availability of health services, and maternal BMI, were

\footnotetext{
* Infants under median length were younger than the rest of the sample. The oldest in this sample was 20 mo old.
}

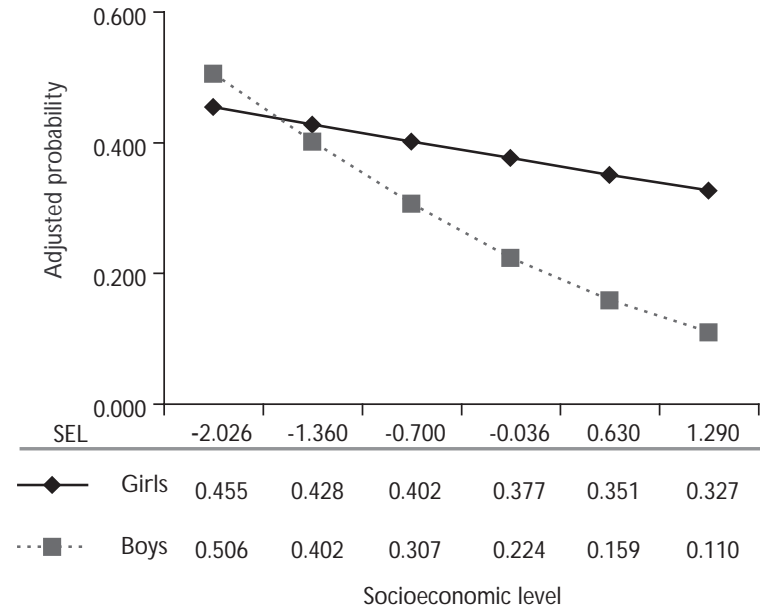

Figure 2. EXCLUSIVE BREAST-FeEding < 4 MONTHS IN Mexico. National Nutrition Survey, Mexico, 1999. INTERACTION BETWEEN SOCIO-ECONOMIC LEVEL AND INFANT SEX (CALCULATED THROUGH A COMPLEX SURVEY REGRESSION MODEL. ADJUSTED FOR MATERNAL ETHNICITY and Infant age, See Table III)

statistically significant $(p \leq 0.05)$. A clear trend of increasing proportions of children ever breast-fed with increasing years of maternal schooling was observed. 
There was a lower proportion of ever breast-fed children in the group of heavier mothers and in those with no health service available.

The percent of infants $\mathrm{EBF}<4$ mo was $25.7 \%$, and for those $\mathrm{EBF}<6$ mo was $20.3 \%$. As expected, prevalence of $\mathrm{EBF}<4$ mo was almost in all categories higher than for $<6 \mathrm{mo}$, except for the Mexico City and for the indigenous women, where these two sets of prevalences did not seem to be different.

There are clear differences in EBF proportions at both time intervals $(<4$ and $<6 \mathrm{mo}$ ) within the four regions, between rural and urban settings, and between ethnic groups (all $p<0.001)$. The south has almost three times the extent of EBF as the Mexico City. There is a clear difference among SEL categories with much higher proportions of EBF in the low compared to the middle or high SEL categories. The probability that employed women feed their infants exclusively at the breast is markedly lower than the observed in those self-reported as unemployed at both time points (both $p<0.03$ ). There are not statistically significant differences in the proportions of EBF, within strata of having a spouse present, number of children, or maternal age, at either studied times $(p \geq 0.17)$.

The association between maternal schooling and prevalence of EBF is negative at both intervals $(p<0.001)$, with a slight disruption of the apparently linear association in the interval between 12 to $14 y$. The higher the maternal schooling the lower the prevalence of EBF, with a sharp decline in the rate of reduction after 14 years of maternal schooling. Over forty percent (41.5) of the women with $<1 \mathrm{y}$ of maternal schooling reported $\mathrm{EBF}<4$ and only $3.7 \%$ do so in the group of mothers with $\geq 14 y$ of schooling. The same pattern is observed for $\mathrm{EBF}<6$. Having health service coverage is negatively associated with the proportion of $\mathrm{EBF}<4 \mathrm{mo}$ and $\mathrm{EBF}<6$ mo (both $p<0.05$ ).

In terms of maternal nutritional status, there is a notably higher proportion of EBF for the shorter $(<$ mean height) and the thinner ( $<$ mean BMI) mothers (all $p<0.001)$. EBF proportions for shorter infants $(<$ mean length) are larger than for longer infants.

Over $10 \%$ more girls $<4$ months were exclusively breast-fed $(31.7 \%)$ than boys $(20.2 \%, p<0.01)$. At $<6$ months, there was still a larger proportion of girls who were EBF, but the difference was smaller $(7.1 \%, p<0.05)$.

Two logistic regression models were developed for complex surveys, to describe the infant's probability of $\mathrm{EBF}<4 \mathrm{mo}$ and $\mathrm{EBF}<6 \mathrm{mo}$ (Table III).

Infant age, and sex, maternal SEL and ethnicity, and the interaction between SEL and infant sex, determined the $p(\mathrm{EBF}<4)$. Maternal schooling and employment were included in the model as relevant

\section{Table III Determinants* OF EXCLUSIVE BREAST-FEeding ${ }^{\ddagger}$ OF INFANTS < THAN 4 AND $<6$ MONTHS OF AGE. National Nutrition Survey, Mexico, 1999}

Variable

Odds Ratio 'P' value

Model 1: Exclusive breast-feeding from birth

to $<4$ months $(<123 d)$

\begin{tabular}{lll} 
Infant age $(\mathrm{d})$ & 0.99 & 0.001 \\
\hline Ethnicity ${ }^{\S}$ (yes=1, no=0) & 2.12 & 0.023 \\
\hline Socio-economic level $\left(\right.$ score $\left.{ }^{\#}\right)$ & 0.84 & 0.326 \\
\hline Infant sex (male=1, female=0) & 0.46 & 0.006 \\
\hline Interaction: Socio-economic level* infant sex & 0.61 & 0.050
\end{tabular}

$n=474 ; N=559639^{\circ}$

Model 2: Exclusive breast-feeding from birth

to $<6$ months $(<183 \mathrm{~d})$

$\begin{array}{lll}\text { Infant age }\left(\leq 95 \mathrm{~d}=0 ;<95 \mathrm{~d}=1^{\S}\right) & 0.47 & 0.044\end{array}$

$\begin{array}{lll}\text { Ethnicity }^{\S}(\mathrm{yes}=1, \mathrm{no}=0) & 3.09 & 0.000\end{array}$

Socio-economic level (score $\left.{ }^{\#}\right) \quad 0.65 \quad 0.000$

\begin{tabular}{lll} 
Maternal employment $^{*}$ & 0.53 & 0.049 \\
\hline Infant length $(\mathrm{cm})$ & 0.94 & 0.056
\end{tabular}

$n=679 ; N=815876^{\circ}$

* Calculated through Complex survey regression models

₹ Exclusive breast-feeding: receiving $0 \mathrm{~N} \mathrm{LY}$ breast-milk (consumption of pharmaceutical products (medicines or vitamin-mineral preparations) were not explored)

\& Speaks a native language

* Calculated through principal components analysis

\& Dichotomous to avoid collinearity

* Reports holding a job or having some economic activity from which she perceived money in exchange, the week prior to the interview

${ }^{\infty} \mathrm{n}=$ Sample size, $\mathrm{N}=$ estimated population size

variables, but were not associated in a statistically significant way with the outcome ( $p=0.97$ and $p=0.15$, respectively). Their inclusion in the regression models markedly changed the estimated regression coefficients of the rest of the variables, and increased the multicollinearity of the model. Thus, we present model $p(\mathrm{EBF}<4)$ without these two variables. All probabilities presented are adjusted for the statistically significant variables in the model.

At $<4 \mathrm{mo}$, the probability of being EBF declined with the child's age, from an estimated $p(\mathrm{EBF}<4)$ of 0.47 at $10 \mathrm{~d}$ of life, to 0.21 at $110 \mathrm{~d}$. Infants of indigenous mothers had almost twice the $p(\mathrm{EBF}<4)(p=0.39)$ compared to those of non indigenous mothers $(p=0.24)$. The association between sex and $p(\mathrm{EBF}<4)$ depended on the SEL of the family. In girls, this probability had a modest decline across the SEL values. It changed little from the lowest $(p(\mathrm{EBF}<4)=0.46)$ to the highest $(p(\mathrm{EBF}<4)=0.33)$ value of the SEL score. In contrast, 
for boys, this probability decreased sharply, from 0.51 in the lowest to 0.11 in the highest SEL. The $p(\mathrm{EBF}<4)$ was unaffected by maternal schooling or employment at this infant age. Maternal schooling was added to the model either as a dichotomous variable, categorized into three groups, as a line or as a curve. None of these forms were associated with $p(\mathrm{EBF}<4)$ and inclusion of either forms created multicollinearity problems in the model.

For infants $<6 \mathrm{mo}$, the $p(\mathrm{EBF}<6)$ was determined by infant's age and length, and by maternal ethnicity, SEL and employment. Again, maternal schooling was not associated with $p(\mathrm{EBF}<6)$. We assessed the pertinence of including age in its linear form, but through the analyses resulted better if age was categorized, using the median as the cutt-ff $(\leq,>95 \mathrm{~d})$. The $p(\mathrm{EFF}<6)$ was larger for younger $(p=0.31)$ than for older infants $(p=0.18)$. The size of the infant, as estimated by length, was inversely associated with $\mathrm{p}(\mathrm{EBF}<6)$. The shortest infants in this age $(52 \mathrm{~cm})$ had a twice the $p \mathrm{EBF}<6$ $(p=0.34)$ than that observed for the largest $(67 \mathrm{~cm})$ infants $(p=0.18)$. Infants of indigenous mothers had three times the $p(\mathrm{EBF}<6)(p=0.34)$ than those of non indigenous mothers $(p=0.15)$. Maternal employment at this age was negatively associated with the outcome. Infants of employed women had a probability of $\mathrm{EBF}<6$ of 0.19 ; and this value was 0.30 for infants of mothers who reported not holding a paid employment the week prior to the interview. Finally, SEL was also inversely related to the $p(\mathrm{EBF}<6)$. This probability was 0.41 in the lowest and 0.17 in the highest SEL.

\section{Discussion}

The NNS-1999 offered the opportunity to ascertain breast-feeding practices in Mexico. The proportion of exclusive breast-feeding for infants $<4 \mathrm{mo}$ is $25.7 \%$, and for those $<6 \mathrm{mo}$ is $20.3 \%$. The percent of infants ever breast-fed is $92.3 \%$. National data on the proportion of exclusive breast-feeding had only been collected once in Mexico prior to 1999. It was on $1979^{21}$ when breastfeeding practices were evaluated by the status quo method, the same method we used in this national survey to estimate prevalences of EBF. We assume that the two surveys are relatively comparable in terms of their estimate of the rates of EBF because both used the same methodology to estimate EBF, and both were national representative surveys drawn form a probabilistic sample proportional to the size and urban: rural population in the country. For the 1979 national survey, data on exclusive breast-feeding (EBF) were presented only for those infants who were breastfed. Our NNS-1999 data derive from all live children
$<2 y$ regardless of their feeding mode. We recalculated the proportions of EBF in 1979 based on all studied children, and estimated that $15.3 \%$ of infants below 3 months of age were fed exclusively at the breast. Over two decades later, $29.4 \%$ of infants $<3$ mo of age are fed exclusively at the breast in Mexico. The estimated change in the proportion of EBF over these two decades represents a two-fold increase in $22 \mathrm{y}$.

Although the rate of improvement was substantial, it is below improvements achieved by other Latin American countries. For example, in Honduras and Nicaragua increases of 7.75 percent points per year were observed from 1985 to 2000 and in Brazil increases of 3.8 percent points per year were documented during the same period (UNICEF*), ${ }^{18}$ while in Mexico the increase reported above was equivalent to 0.75 percent point per year. Should these rates remain unchanged, it would take $93 y$ for Mexico to increase to $100 \%$ of EBF $<4$ mo; whereas Nicaragua would need only $7.5 y$ and Brazil $15.3 y$.

The percentage of infants ever breast-fed in Mexico had been ascertained more recently and increased from 86.3 in 1988 (NNS-I) to 92.3 in this National 1999 survey. This is an important improvement which is probably the result of the breast-feeding initiation promotion in maternity hospitals.

In relation to the duration of breast-feeding, two previous national surveys ${ }^{19,23}$ revealed a median of 8.7 mo in $1976,{ }^{19}$ a mean of 10.5 mo in $1987 .{ }^{23}$ The present NNS-1999 reports a median of 9 mo; i.e., no meaningful change. The 1976 and 1987 surveys had different time frames than the NNS-1999 to estimate duration of breast-feeding. In the two previous surveys, mothers in their reproductive years were asked for how long they breast-fed their last child. In the NNS-1999 we collected child feeding practices for live children $<24$ mo of age.

Even when $20 \%$ of the children were still breastfed at 23 mo in the NNS-1999, half of all infants $<24$ months had stopped breast-feeding at 9 mo. Thus, no underestimation of the median duration could have been caused by having still $20 \%$ breast-fed infants at 23 mo.

The results of the NNS-1999 show that the proportion of exclusive breast-fed infants is higher in the south region of Mexico, in the rural communities,

* Bolivia, Brazil, Chile, Colombia, Dominican Republic, Ecuador, El Salvador, Guatemala, Honduras, Nicaragua, Paraguay, and Perú. 
in the indigenous population, in the low SEL, in infants of unemployed mothers or whose mother had either no schooling, had no health services, were thinner or shorter. The percentage of exclusive breast-feeding is also larger for smaller babies and for girls. These proportions range from $28.3 \%$ to $48.2 \%$ for $\mathrm{EBF}<4$, and from $22.7 \%$ to $48.4 \%$ for $\mathrm{EBF}<6$ mo (See Table II).

Two groups of determinants of exclusive breastfeeding appear relevant: a) maternal characteristics (ethnicity, employment and socio-economic level), and b) infant characteristics (age, gender, and size as determined by length as opposed to by weight).

Previous research has documented better practices in rural Mexico ${ }^{33}$ and in less educated mothers. ${ }^{20}$ In our bivariate analysis, we also found these trends. However, when we use multiple regression models adjusting for several variables, factors such as rural/ urban location were no longer associated with breastfeeding practices. Clearly, the analytical strategy used modifies the inferences drawn from the data.

Indigenous women are spread throughout Mexico, but concentrate in the south where $73.8 \%$ of the total indigenous population lives. Ethnicity is a strong predictor of $\mathrm{EBF}<4$ in Mexico, even after controlling for the mother's socio-economic level. This finding suggests that it is not only availability of resources, as indicated by SEL, which influence feeding practices, but other factors, such as infant rearing practices or culture, determine infant feeding mode as well. The influence ethnicity has on the prevalence of exclusive breast-feeding is observed for the entire interval studied; i.e., the first 6 mo of life. The WHO recommends EBF for $6 \mathrm{mo}$, and Mexican indigenous women are more in agreement with this recommendation than their non-indigenous counterparts.

Our results also show that the probability of exclusive breast-feeding $<4$ mo is influenced by infant's sex. Girls are more commonly exclusively breast-fed than boys. Pérez-Escamilla and co-workers ${ }^{34}$ have reported that girls are more frequently exclusively breastfed than boys in Brazil and Honduras, but had not observed this in Mexico. Adair and co-workers ${ }^{35}$ in the Philippines found that girls were fully breastfed more frequently than boys. An explanation offered by both groups of authors relate to the mothers' perception about size of the infants (boys being larger), or to gender bias.

Gender bias may be related to parental involvement with their children in different living conditions. This is explained by the Trivers and Willard ${ }^{36}$ theory which predicts that parents living in good conditions will bias their investments to sons, whereas those living in poor conditions will bias their investment to- wards girls. For the Trivers and Willard ${ }^{36}$ theory to hold, an interaction between condition and gender should exist. We observed an interaction between gender and our indicator of socio-economic condition as these relate to the $p \mathrm{EBF}<4$ mo. We do not know the reason why mothers introduce complementary foods earlier to boys than to girls; but if we assume they do so because they believe boys need more than girls, then our study finds support for this theory. Gender bias may be related to the mother trying to favor boys by feeding them other foods earlier under the assumption that it is beneficial for their growth. Paradoxically such gender bias, should it exist, would be counterproductive for boys because early introduction of foods to the infant is associated with increased morbidity. ${ }^{37}$

The size of an infant may be a cue to the mother, influencing her infant's feeding practices. Size may shift her decision in either direction. In one scenario, if the exclusively breastfed child is large, the mother might interpret this as her milk production being sufficient to support such growth, and be persuaded to continue exclusive breast-feeding. This was observed in the Philippines ${ }^{35}$ where fatter infants (larger ponderal index $\left.\left(\mathrm{g} / \mathrm{cm}^{3}\right)\right)$ were more likely to be $\mathrm{EBF}<6 \mathrm{mo}$ than the thinner babies. But in an alternative scenario, growth (size) could be a signal for the nursing mother indicating a growing need for foods. In this case, larger infants would be fed complementary foods earlier than smaller ones.

Support for this last scenario was observed in the present analyses where the probability of being exclusive breastfed $<6$ mo decreased as infant length increased.

There is evidence that Latin American nursing women think that bigger babies need more food. Picado and coworkers ${ }^{38}$ found that Nicaraguan lactating mothers consider exclusive breast-feeding (in infants $<1 y$ ) insufficient to support growth, and inconvenient for the nursing mother. Unfortunately no information is given on the age of the child at which the mother considers EBF to be insufficient. This concept would most probably be wrong for a two-month old baby, and quite accurate for an eleven-month old one; both $<1 \mathrm{y}$.

Reverse causality has been documented to explain the negative association between the size (nutritional status) of the infant and prolonged breast-feeding. It has been observed that mothers decide not to wean the sicker infants and extend the duration of breastfeeding to protect the weaker child. ${ }^{739,40}$ This has been described for infants older that 6 mo and for any and not for exclusive breast-feeding. Thus, reverse causality cannot explain the greater $\mathrm{p}(\mathrm{EBF}<6)$ observed in our data. 
Cultural, as well as practical issues influence maternal infant feeding practices. Employment status, a variable in our model for exclusive breast-feeding $<6$ mo, impose real time constraints for mothers. The introduction of foods or liquids to the breast-fed infants' diet might be a strategy for the working mother to reduce the time spent breast-feeding, releasing more time for work. In a study of time budgets of unemployed mothers, ${ }^{41}$ the introduction of complementary feeds to the breast-fed infant observed was reported to increase, rather than decrease the time spent feeding the baby. In such context, time constraint may not be a real issue. The inferences done by Cohen and co-workers apply for mothers not working outside their home. However; in the case of employed mothers, they can be substituted by another person to bottle or complementary feed their infants releasing real time to work. There is ample evidence in the literature that employed nursing mothers or those planning to return to work, breast-feed less frequently their infants and are less likely to exclusively breast-feed..$^{37,38,42}$ Combining nursing and employment is not a simple process. Employed mothers need accurate and practical advice, permission to breast-feed their infants, a private place to extract milk in their working place, flexible working hours, and encouragement and support from peers and family to breast-feed as recommended by the WHO. Unless decisive and targeted breast-feeding protection and promotion for employed mothers is implemented, breast-feeding rates are expected to be lower than those found for non-employed mothers. An intervention trial in Chile ${ }^{43}$ shows that improving working conditions and lactation knowledge of nursing mothers, such as a place to extract and store milk, anticipatory counseling, and monthly follow-ups, can increase the percentage of exclusive breast-feeding during the first six months of life.

The Baby Friendly Hospital Initiative (BFHI), put forth by UNICEF and WHO has been implemented in Mexico for over a decade. ${ }^{44}$ No formal evaluation of its impact has been conducted in the country, but it has probably played a role in the changes observed and reported here, especially in improving the rates of ever breast-feeding or initiation. This initiative has been observed to improve rates of initiation and duration of breast-feeding ${ }^{45,46}$ and the likelihood of improved rates of exclusive and full breast-feeding at 3 mo.

Clearly, a more efficient implementation of the $\mathrm{BFHI}$ in Mexico, as well as decisive and unambiguous breast-feeding promotion and protection is needed to improve the poor practices observed in Mexico. Otherwise, it would take us almost $100 \mathrm{y}$ to reach the WHO recommendation of exclusively breast-feed all infants $<4$ mo. $^{*}$

A limitation of our study is the lack of qualitative information regarding the reasons behind infant feeding decisions. We can confidently state who has better infant feeding practices, but we do not know why, which is an indispensable piece of information to design potentially effective breast-feeding promotion programs. Neither do we know who the actors are in these decision making process. Our data do not provide information on the specific role of the family members or the health services -private or governmental-, in the mother's decision to breast-feed. But clearly, these potential actors have not provided enough quality and timely breast-feeding protection to have had meaningful impact in the country's breast-feeding practices in the last two decades as other countries such as Honduras, Nicaragua or Brazil have probably done.

Another limitation of our study, shared by studies using the status quo method in cross sectional studies, is the inference about the prevalence of EBF. Using the status quo methodology, infants are classified as exclusively breast-fed if nothing but breast milk was consumed the day and night prior to the interview. This does not imply that these infants had never received any other liquid or food, or that they have always been fed the same way. If there is an interest in estimating the prevalence of those infants who have been EBF all their life, a modified methodology must be used, and the status quo method, as used today, would probably underestimate such prevalence. The magnitude of this bias would depend on the type and frequency of the reversibility of the infant feeding practices in the studied populations.

Nonetheless, with the available national information we have a better idea of what type of breast-feeding promotion is needed (exclusive breast-feeding all infants $<6 \mathrm{mo}$ ), who needs it the most (employed, highly educated, non-indigenous women of medium SEL and not living in the south, as well as those bearing large babies or boys), and when is mostly needed (prior to initiate breast-feeding).

Qualitative research in nursing and non-nursing mothers is needed to tailor better breast-feeding promotion and protection programs in Mexico. Such programs are urgently needed to improve infant feeding practices. By doing so we may expect better infant health, survival, and cognitive development. Mothers

\footnotetext{
* And even longer for $<6 \mathrm{mo}$, the current recommendation.
} 
would benefit as well. Fertility may be reduced by intense breast-feeding, a powerful family planning strategy in developing countries. Also, mothers who breast-feed exclusively at the breast for the recommended WHO-duration, would lose more weight. In the face of the large overweight prevalence increase in the world and in Mexico, this may be an excellent measure against increased weight gain with pregnancy.

\section{References}

1. Institute of Medicine, Subcommittee on N utrition During Lactation, Committee on N utritional Status during Pregnancy and Lactation, Food and N utrition Board. N utrition during Lactation. W ashington, DC: $N$ ational A cademy Press, 1991.

2.Victora C G, Vaughan P, Lombardi C, Fuchs S, G igante L, Smith P et al. Evidence for protection by breast-feeding against infant deaths from infectious diseases in Brazil. Lancet 1987;A ug 8;2(8554):319-322. 3.Yoon PW, Black R, Moulton L, Becker S. Effect of not breastfeeding on the risk of diarrheal and respiratory mortality in children under 2 years of age in Metro Cebu, the Philippines. Am J Epidemiol 1996;143: 1142-1148.

4. López-A larcón M,Villalpando S, Fajardo A. Breast-feeding lowers the frequency and duration of acute respiratory infection and diarrhea in infants under six months of age.J N utr 1997;127:436-443.

5. Feachem R, Koblinsky M. Inter ventions for the control of diarrhoeal diseases among young children: Promotion of breast-feeding. Bull W orld Health O rgan 1984;62(2):271-294.

6. Martínez JC, Habicht JP,A shworth A, Kirkwood B.W eaning in Southern Brazil: Is There a "W eanling's Dilemma"? J N utr 1994;124:1189-1198.

7. Marquis GS, Habicht JP, Lanata CF, Black RE, Rasmussen KM. Breast milk or animal-product foods improve linear growth of Peruvian toddlers consuming marginal diets. Am J C lin N utr 1997;66:1102-1109. 8.Anderson JW, Johnstone B, Remley D. Breast-feeding and cognitive development:A meta-analysis. Am J C lin N utr 1999;70:525-535. 9. D ewey KG. Is breastfeeding protective against child obesity? J Hum Lact 2003 Feb; 19(1):9-18.

10. Collaborative Group on Hormonal Factors in Breast Cancer. Breast cancer and breastfeeding: Collaborative reanalysis of individual data from 47 epidemiological studies in 30 countries, including 50302 women with breast cancer and 96973 women without the disease. Lancet 2002;360(9328):187-195.

11.Tovar-G uzmán V, Hernández-Girón C, Lazcano-Ponce E, Romieu I, Hernández-Avila M. Breast cancer in Mexican women:An epidemiological study with cervical cancer control. Rev Saude Publica 2000;34(2):113-119.

12. Romieu I, Hernández-Avila M, Lazcano E, López L, Romero-Jaime R. Breast cancer and lactation history in mexican women.Am J

Epidemiol 1996;143(6):543-552.

13. McN eilly AS. Lactational control of reproduction. Reprod Fertil Dev 2001;13:583-590.

14. Howie PW. N atural regulation of fertility. Br Med Bull 1993;49: 182-199.

15. D ewey K, C ohen R, Landa-Rivera L, C anahuati J, Brown K. Effects of age at introduction of complementary foods to breast-fed infants on duration of lactational amenorrhoea in Honduran women. Am J C lin $N$ utr 1997;65:1403-1409.

16. Dewey K, C ohen R, Brown K, Landa-Rivera L. Effects of exclusive breastfeeding for four versus six months on maternal nutritional status and infant motor development: Results of two randomised trials in Honduras. J N utr 2001;131:262-267.

17. Rivera JA, Barquera S, C ampirano F, C ampos I, Safdie M, Tovar V. Epidemiological and nutritional transition in Mexico: Rapid increase of non-communicable chronic diseases and obesity. Public Health $\mathrm{N}$ utr 2002;5(1A):113-122.

18. UN ICEF End Decade Databases - Breastfeeding Available from: http://childinfo.org/eddb/brfeed/grpexamr.htm. C onsulted on 6/19/2000. 19. N otzon F. Trends in infant feeding in developing countries. Pediatrics 1984;74(Suppl):648-665.

20. Gómez-D antés H, Garnica ME, Sepúlveda J,Valdespino-Gómez JL, Lam N, Herrera M. Patrones de lactancia y ablactación en México. Encuesta N acional de Salud 1986. Salud Publica Mex 1989;31:725-734. 21. Dimond HJ,A shworth A. Infant feeding practices in Kenya, Mexico and Malaysia.The rarity of the exclusively breast-fed infant. Human N utr 1987;41A:51-64.

22.Y sunza O A. El abandono de la lactancia materna en México. I. Tendencias recientes. Rev Invest Clin 1986;3(supl):41-46.

23. Anonymous. Mexico 1987: Results from the Demographic and Health survey (D HS). Stud Fam Plann 1990;21:181-185.

24. Long-D unlap K, Rivera J, Rivera M, Hernández-Avila M, Lezana MA. Feeding patterns of Mexican infants recorded in the $1988 \mathrm{~N}$ ational N utrition Survey. Salud Pública Mex 1995;37:120-129.

25. 0 rganización Mundial de la Salud. 54a. Asamblea Mundial de la Salud. Punto 13.1 del orden del día provisional. Estrategia mundial para la alimentación del lactante y del niño pequeño. Informe de la Secretaría. Ginebra: O MS, 2001;A54/7.

26. Rivera J, Shamah T,Villalpando S, G onzález-C ossío T, Hernández B, Sepúlveda J. Encuesta $N$ acional de Nutrición 1999. Estado N utricio de niños y Mujeres en México. Cuernavaca, Morelos, México: IN SP, 2001. 27. Lung'aho M, Huffman SL, Labbok MH, Sommerfelt E, Baker J.Tool kit for monitoring and evaluating breastfeeding practices and programs. W ashington, DC:W ellstart International, Expanded Promotion of Breastfeeding Program, Septiembre 1996; USAID Policy \& Technical Monographs.

28. Hosmer D Jr, Lemeshow S. Applied survival analysis. N ueva York (N Y): John W iley and Sens, 1999:28-31.

29. Lehtonen R, Pahkinen E. Practical methods for design and analysis of complex surveys. Chichester, England: John W iley \& Sons, 1995:269-281. 30. Hair JF,Anderson R, Tatham R, Black W. Multivariate data analysis with readings. 3a ed. N ueva York (N Y): Macmillan Publishing Company, 1992:223-253.

31. Hosmer DW, Lemeshow S. A pplied logistic regression. N uevaYork (NY):W iley \& Sons, 1989:140-145.

32. Gujarati D. Basic econometrics. N uevaYork (N Y): Mc Graw Hill, 1997:330-334.

33. Pérez-Escamilla R. Breastfeeding in Africa and the Latin American and Caribbean Region:The potential role of ubanisation. J Trop Pediactr 1994;40:137-143.

34. Pérez-Escamilla R, Lutter CH, Segall AM, Rivera A, Treviño-Siller S, Sanghvi T. Exclusive breast-feeding duration is associated with attitudinal, socioeconomic and biocultural determinants in three Latin American countries. J N utr 1995;125:2972-2984.

35. A dair LS, Popkin B, G uilkey DK. The duration of breast-feeding: How is it affected by biological, sociodemographic, health sector, and food industry factors? Demography 1993;30:63-80.

36. Trivers RL,W illard DE. N atural selection of parental ability to vary the sex ratio of offspring. Science 1973;179:90-92. 
37. Brown K, Black RE, López-Romaña G, Credd de Kanashiro H. Infantfeeding practices and their relationship with diarrhoeal and other diseases in Huascar (Lima) Perú. Pediatrics 1989;83:31-40.

38. Picado J, O Ison C, Rasmussen KM. Metodología combinada para entender la duración del amamantamiento en barrios pobres de Managua, N icaragua. Rev Panam Salud Publica 1997;2:398-407.

39. Simondon KB, Simondon F, Costes R, D elaunay V, Diallo A. Breastfeeding is associated with improved growth in length, but not weight, in rural Senegalese toddlers. Am J C lin N utr 2001;73:959-967.

40. Habicht JP.The association between prolonged breastfeeding and poor growth-W hat are the implications? Adv Exp Med Biol 2000;478:193-200.

41. Cohen RJ, Haddix K, Hurtado E, D ewey KG. Maternal activity budgets: Feasibility of exclusive breastfeeding for six months among urban women in Honduras. Soc Sci Med 1995:41:527-536.

42. Roe B, W hittington L, Fein SB, Teisl MF. Is there a competition between breast-feeding and maternal employment? D emography 1999:36:157-171.
43.Valdes V, Pugin E, Schooley J, C atalán S,A ravena R. C linical support can make a difference in exclusive breastfeeding success among working women. J Trop Pediatr 2000;46:149-154.

44. Secretaría de Salud. C reación del Comité N acional de Lactancia Materna. México, DF: Diario 0 ficial de la Federación, 1991; Acuerdo N úmero 95 de la Secretaría de Salud.

45. Fairbank L, O 'Meara S, Renfrew MJ,W oolridge M, Sowden AJ, Lister-Sharp D.A systematic review to evaluate the effectiveness of interventions to promote the initiation of breastfeeding. Health Technology Assess 2000;4(25):1-171.

46. Kramer MS, Chalmers B, Hodnett ED, Sevkovskaya Z, D zikovich I, Shapiro $S$ et al. Promotion of breastfeeding intervention trial (PRO BIT): A randomised trial in the Republic of Belarus. JAMA 2001;285:413-420. 